(MIT), Schwaiger joined the Forschungszentrum Karlsruhe, Germany, in 2004 and then moved to a management consulting firm in 2007. She joined KIT in 2010. Her research interests range from deformation mechanisms in metals and the mechanics of small-scale materials and structures to biomechanics and mechanical metamaterials. Her research aims to develop a mechanism-based understanding of deformation and failure of materials, and to determine principles for the design toward improved strength and damage tolerance. Schwaiger has (co-)authored more than 50 publications, given more than 30 invited presentations at conferences, and co-organized 10 international symposia and workshops.
Subhash L. Shinde joined the Center for Sustainable Energy at the University of Notre Dame (ND Energy) in November 2016 as the associate director.

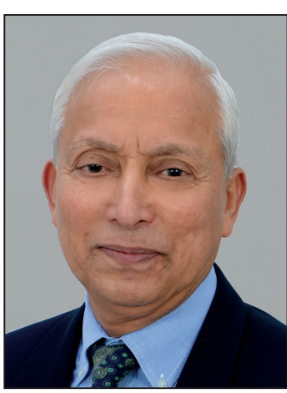

He leads ND Energy's research initiatives in research and global development and corporate programs. He received his BTech and MTech degrees in metallurgical engineering from the Indian Institute of Technology Bombay, India, and his $\mathrm{PhD}$ degree in materials science from Stanford University, USA.
Previously, he held various leadership positions in research for 18 years in the Microelectronics Division of the IBM T.J. Watson Research Center, USA. He was on the research staff and then a manager of the Concentrating Solar Technologies Group at Sandia National Laboratories, USA, from 2004 until 2012. Shinde has more than 40 publications, including three edited books and a book chapter. He holds more than 65 US patents and another 18 internationally. His research interests include advanced materials for efficient energy-conversion applications. He has given several invited presentations, and has been a symposium organizer for several MRS symposia.

\title{
MRS invites nominations for awards program
}

$\mathrm{T}$ he Materials Research Society (MRS) is seeking nominations for the Von Hippel Award, the David Turnbull Lectureship, the MRS Medal, the Materials Theory Award, the MRS Nelson "Buck" Robinson Science and Technology Award for Renewable Energy, and The Kavli Foundation Early Career Lectureship in Materials Science. The nomination site is open March 1-April 1, 2018. These awards will be presented at the 2018 MRS Fall Meeting, November 25-30, in Boston.

The MRS Awards Program recognizes outstanding contributors to the progress of materials research and acknowledges their exciting and profound accomplishments. Nomination forms and details about eligibility and nomination criteria are available from the Materials Research Society website at www.mrs.org/awards.

\section{Von Hippel Award acknowledges outstanding interdisciplinary work in materials research}

The Von Hippel Award, first presented to Arthur R. von Hippel, whose interdisciplinary and pioneering research typified the spirit of the award, is the
Society's highest honor. The recipient is recognized for brilliance and originality of intellect, combined with vision that transcends the boundaries of conventional scientific disciplines. The award includes a \$10,000 cash prize, honorary membership in MRS, and a unique trophy - a mounted ruby laser crystal, symbolizing the many faceted nature of materials research.

\section{Turnbull Lectureship honors career of an outstanding researcher and communicator}

The David Turnbull Lectureship recognizes the career of a scientist who has made outstanding contributions to understanding materials phenomena and properties through research, writing, and lecturing, as exemplified by the life work of David Turnbull. While honoring the accomplishments of the recipient, the David Turnbull Lectureship is intended to support and enrich the materials research community. The recipient will give a technical lecture of broad appeal at a designated session of the 2018 MRS Fall Meeting. The Turnbull Lecturer will receive a $\$ 5,000$ honorarium and a citation plaque.

\section{MRS Medal recognizes recent discovery or advancement in materials science}

The MRS Medal recognizes an exceptional achievement by an individual in materials research. The Medal is awarded for a specific outstanding recent discovery (approximately in last 10 years) or advancement that is expected to have a major impact on the progress of any materials-related field. The award consists of a $\$ 5,000$ cash prize, an engraved and mounted medal, and a citation certificate.

\section{Materials Theory Award honors advances made in materials structure and behavior}

The Materials Theory Award recognizes exceptional advances made by materials theory to the fundamental understanding of the structure and behavior of materials. This award is intended to honor both those who have pioneered the development of a new theoretical approach and those who have used existing approaches to provide significant new insight into materials behavior. The annual award consists of a $\$ 5,000$ cash prize, a presentation trophy, and a 
certificate. MRS acknowledges the generosity of Toh-Ming Lu and Gwo-Ching Wang in endowing this award.

\section{MRS Nelson "Buck" Robinson}

Science and Technology Award

\section{for Renewable Energy}

This new award recognizes a student (bachelor's, master's, or PhD), postdoc, or other young professional through five years following the highest degree attained for the development of sustainable solutions for the realization of renewable sources of energy. The annual award consists of a $\$ 5,000$ honorarium, Meeting registration, annual MRS membership, and reasonable travel expenses to attend the Meeting at which the award is presented. MRS acknowledges Sophie Robinson for endowing this award in memory of her father, Nelson Buck Robinson.
The Kavli Foundation Early Career Lectureship in Materials Science recognizes significant contributions

This Lectureship is an honor that recognizes significant novel contributions to materials science by a researcher in the early stages of his/her career. The award includes a \$1,000 honorarium and a twonight hotel stay to attend the Meeting to present a talk.

\section{NICE 2018: 4th International Conference on Bioinspired and Biobased} Chemistry \& Materials to be held October 14-17 www.unice.fr/nice-conference

$\mathrm{N}$ ature Inspires Creativity Engineers (NICE) 2018, the 4th International Conference on Bioinspired and Biobased Chemistry \& Materials, will be held October 14-17 in Nice, France.

By taking inspiration from nature, scientists can engineer artificial materials that produce new solutions and opportunities for industrial, environmental, and medicinal applications. However, the potential scope of impact of bioinspired materials goes well beyond these domains. The conference's objective is to share new developments in the growing field of bioinspired chemistry and materials and to understand new challenges that are being faced in this field of research. The conference encompasses chemistry, biology, and physics, and gives a multidisciplinary overview of biomimetic approaches to engineering new materials and systems. The aim is to find eco-friendly, green, and sustainable solutions to materials challenges.

Among the topics to be discussed are green chemistry, nanomaterials, renewable energy, stimuli-responsive materials, adhesive/anti-adhesive materials, functional polymers, biobased chemistry, and materials.

The plenary speakers are Lei Jiang of the Institute of Chemistry, Chinese Academy of Sciences, China, and Valentine Vullev of the University of California, Riverside, USA. The conference will also feature keynote speakers, oral presentations, poster sessions, and workshops.

The call for abstracts deadline is May 31. Early bird registration ends June 30. More information can be accessed at www.unice.fr/nice-conference or by email at contact@nice-conference.com.

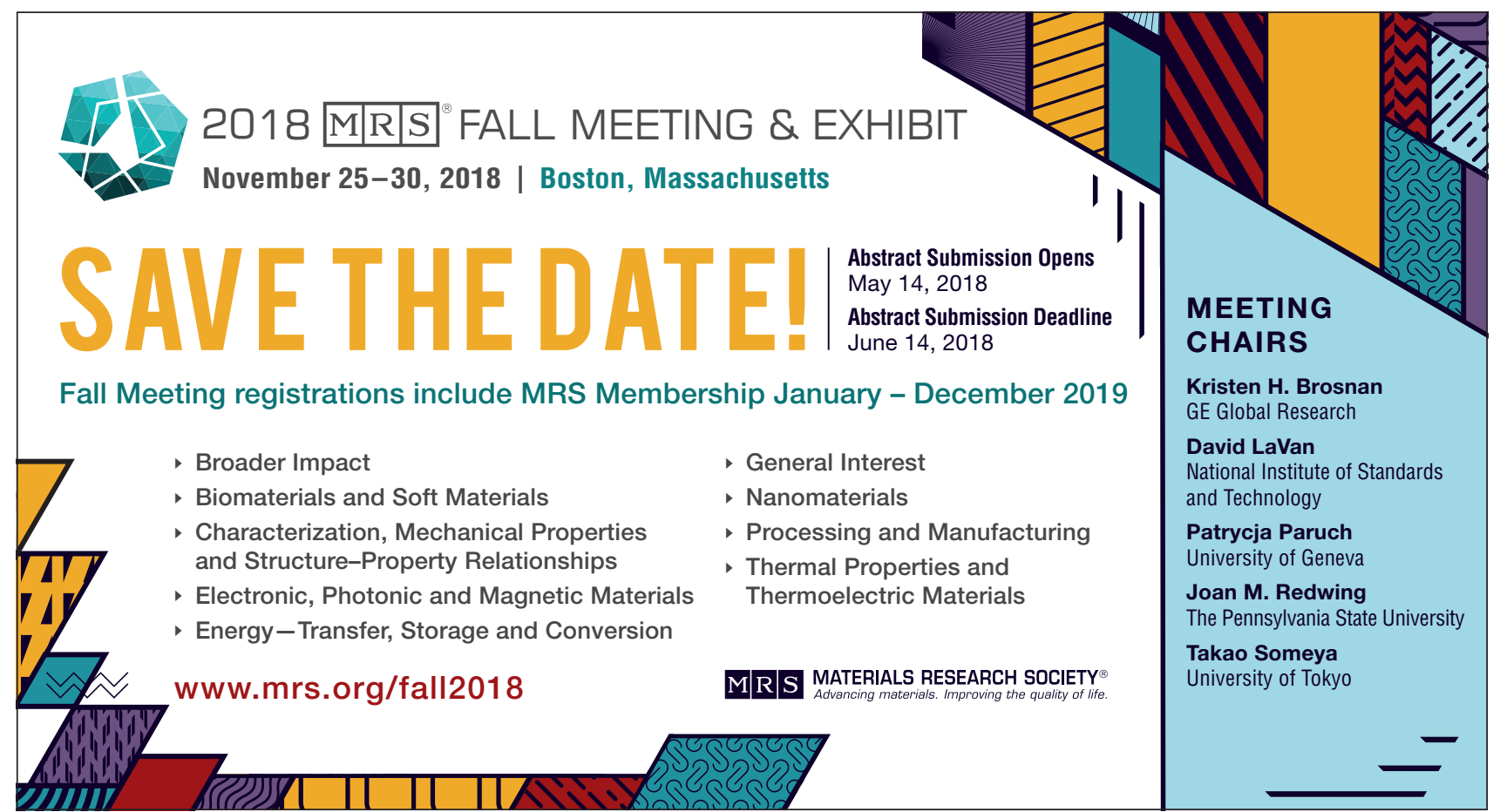

